\title{
Citizenship information needs in the UK: results of a national survey of the general public by personal doorstep interview
}

\author{
Rita Marcella and Graeme Baxter \\ School of Information and Media \\ The Robert Gordon University \\ Faculty of Management Building \\ Garthdee Road, Aberdeen \\ AB10 7QE \\ Email: r.marcella@rgu.ac.uk
}

\begin{abstract}
This paper reports the results of the second stage of the Citizenship Information research project funded by the BLR\&IC: a national survey, by personal doorstep interview, of the citizenship information needs of 898 members of the UK public. Major findings include: that the public obtain most of their information on current issues via the media, and that they generally feel well informed on these issues. The public believe, however, that government is not doing enough to inform them about the Single European Currency and local council cutbacks. Small proportions of the sample had encountered problems in relation to employment, education, housing or welfare benefits and had consulted a range of information sources in order to solve these problems. Over a quarter of respondents had experienced disadvantage through a lack of access to information. Significant proportions of respondents were poorly informed about legal rights, welfare benefits and local politics. A highly significant majority (91.7\%) believed that freedom of information was important for exercising their rights as citizens. Although access to computers in the home is presently limited, the majority of respondents indicated a willingness to use computers to vote and interact with government. Public libraries were the preferred source of government information and were seen as appropriate locations for a range of other types of citizenship information.
\end{abstract}




\section{Introduction and Methodology}

The April 1999 issue of Aslib Proceedings contained a report ${ }^{1}$ of the results of the first stage of the Citizenship Information research project funded by the British Library Research and Innovation Centre, a questionnaire-based survey of a sample of the UK population designed to elicit preliminary data on their use of and need for citizenship information. These questionnaires had been distributed in public libraries, Citizens Advice Bureaux (CABx) and other generalist information and advice agencies throughout the 13 Government Office Regions of the UK.

This current paper reports the results of the second stage of the project: a complementary national survey of the public's citizenship information needs, this time by personal doorstep interview. These interviews were designed to elicit more qualitative, extended and individual responses, and to form a more in-depth and less pre-determined set of data. In conducting the interviews at people's homes, away from the 'institutional' setting of the initial survey, it was expected that any deficiencies in the first survey would be overcome by reaching, for example, the less literate respondent and those from lower social grades.

To conduct the interviews, the project team employed undergraduate and postgraduate librarianship and information studies students from library schools throughout the country. Interviews took place in 12 of the 13 UK regions (the exception being Merseyside) and in the same towns and cities in which the Stage 1 questionnaires had been disseminated. Each interviewer was provided with socio-economic and population data for their allocated town/city taken from the 1991 UK Census Small Area Statistics ${ }^{2}$, and was asked to identify five local government electoral wards in which the survey would take place: the ward containing the highest percentage of residents belonging to Standard Occupational Classification $^{3}$ Social Classes IV and V (partly skilled and unskilled occupations), the ward with the lowest percentage of Classes IV and V, and three other wards spread across the cumulative population figures for the town/city.

Each interviewer was asked to complete 15 interviews in each of the five wards - a total of 75 interviews in each town/city. All were successful, with the exception of one interviewer who fell two short of the desired quota, therefore 898 interviews were completed. The interviews took place between May and November 1998. The interviewers were instructed to use the random walk sample method, whereby they randomly selected a starting point within each ward and proceeded to attempt an interview at every 7th household within that ward until the 
required quota had been reached. Detailed instructions were provided on how to deal with road junctions, vacant households, blocks of flats, offices and commercial premises, etc. The response rate of this method in individual wards ranged from $31.9 \%$ (i.e. one successful interview obtained at every third household visited) to $4.9 \%$ (one in every twenty homes visited).

Table 1 illustrates the gender and age group of the respondents. The female-male ratio was significantly greater than that occurring nationally $\left(51 \%-49 \%{ }^{4}\right)$ and in the first survey. The proportion of older respondents ( $40 \%$ aged 55 or over) was also substantially greater than the national percentage of $26 \%$ and that in the initial survey.

Table 1. Gender and age of respondents

\begin{tabular}{|c|c|c|c|c|c|}
\hline \multirow[t]{2}{*}{ Age Group } & \multirow[t]{2}{*}{ Male } & \multirow[t]{2}{*}{ Female } & \multirow{2}{*}{$\begin{array}{c}\text { Not } \\
\text { specified }\end{array}$} & \multicolumn{2}{|c|}{ Totals } \\
\hline & & & & No. & $\%$ \\
\hline $16-19$ & 18 & 24 & - & 42 & 4.7 \\
\hline $20-29$ & 72 & 72 & - & 144 & 16.0 \\
\hline $30-44$ & 75 & 149 & - & 224 & 24.9 \\
\hline $45-54$ & 40 & 82 & 1 & 123 & 13.7 \\
\hline $55-64$ & 54 & 77 & 1 & 132 & 14.7 \\
\hline $65-74$ & 52 & 75 & - & 127 & 14.1 \\
\hline 75 or over & 35 & 66 & - & 101 & 11.2 \\
\hline Age not specified & 1 & 4 & - & 5 & 0.6 \\
\hline Totals & $\begin{array}{c}347 \\
(38.6 \%)\end{array}$ & $\begin{array}{c}549 \\
(61.1 \%)\end{array}$ & $\begin{array}{c}2 \\
(0.2 \%)\end{array}$ & 898 & 100.0 \\
\hline
\end{tabular}

In total, $56(6.2 \%)$ of the respondents belonged to an ethnic minority group, while 118 $(13.1 \%)$ indicated that they were disabled in some way. $16.7 \%$ lived in rural areas. Just over a quarter had completed an undergraduate or higher degree course, almost $23 \%$ had completed a further education course, while just over half had received no education beyond school. Over $56 \%$ of the respondents were economically inactive (i.e. student, retired, running a home or permanently unable to work), slightly greater than the national figure of $51.1 \%^{6}$; however, as the national figure includes all people under 16 , who were excluded from this survey, then it becomes clear that the respondents came to a greater extent proportionally from the economically inactive groups than for the UK as a whole. These data would suggest that the doorstep interview methodology has reached greater proportions of those groups deemed to be in danger of social exclusion, providing results that are particularly revealing. They also complement those of the first survey where a more dynamic and arguably more 'informed' group of respondents was achieved. 


\section{Survey results}

Respondents were initially asked to identify what they believed to be the single most important issue in UK current affairs at the time of the survey. A wide range of issues was cited, although the top ten responses were: the Northern Ireland situation; the state of the education system; health issues and the National Health Service; the European Union and UK participation in European Monetary Union; the UK economy; unemployment; law and order; the football World Cup; the environment; and the state of the Labour government. There were some significant demographic differences in the response to this question. When compared with female respondents, males placed greater importance on European issues (+6.0 percentage points) and unemployment (+4.3), but less importance on health (-8.6) and education (-5.4). Younger respondents appeared to have less interest in health and (perhaps surprisingly) Europe but more interest in education. Amongst the better-educated respondents there was more interest in economic and environmental issues but less interest in the state of the NHS.

Respondents were asked from which source they had obtained most of their information on their chosen current affairs issue. The media dominated overall for subjects, with at least one form (television, radio or newspapers) being cited by over $75 \%$ of respondents in each case. Use of television as the main information source was greater among the manual and unskilled workers, while use of newspapers was greater amongst those with professional and managerial occupations.

Most respondents felt well or very well informed on the main issues identified, although over $15 \%$ in each case felt poorly informed about Europe, Northern Ireland, health, law and order, and the environment. Women tended to feel less well informed than men; while those who had received a better education felt better informed than the other respondents. Despite feeling well informed, significant proportions (over a third in each case) wanted to find out more about education, Europe, the environment, health, unemployment, the economy, Northern Ireland and law and order. When asked where they would most likely go to obtain further information, high proportions indicated that they would approach public libraries. Indeed, libraries were seen as the most important single resource for the environment (46.7\%), education (38.8\%) and health (29.3\%), and an important source of information on employment, Europe, law and order and Northern Ireland. 
Respondents were asked if their chosen issue significantly affected their own lives. While the economy (76.7\%), health (69.6\%), the environment (69.6\%), education (67\%), Europe (60.5\%), unemployment (57.9\%), and law and order (54.5\%) were deemed by the majority of respondents to have an impact on their lives, the other topics were felt to be less central. However, of the Northern Ireland (i.e. Belfast) respondents, $66.7 \%$ felt the local political situation significantly affected their own lives.

The next part of the survey consisted of a more detailed investigation of three current issues chosen by the researchers as representative of citizenship information need at international, national and local levels: the Single European Currency, the BSE crisis and local government financial cutbacks.

Just under $75 \%$ of respondents indicated that they would like to find out more about European Monetary Union, with female respondents displaying a greater interest than males (+10.2 points). The mass media $(38.7 \%)$ and public libraries $(21.7 \%)$ would be the most popular sources of information, followed by a government information programme (8.7\%). The vast majority $(80.4 \%)$ felt that the government was not doing enough to inform the public about the Single Currency.

The majority of respondents $(59.2 \%)$ felt that they were well informed about BSE. The media $(26.6 \%)$ and public libraries $(19.4 \%)$ were again the most likely sources for those who felt poorly informed, with doctors and other health professionals (7.9\%) forming the major alternative source, particularly for women and the less well educated. A slight majority (55.2\%) felt that the government was not doing enough to inform the public about BSE. When asked how they might make their own feelings known to the government on this issue, the preferred methods were contacting a local MP (38.6\%) or a government minister or department (10\%), although a large proportion (35.6\%) were not interested in making their own feelings known.

Almost two-thirds (63.4\%) of respondents felt poorly informed about local government cutbacks, with the most likely sources of additional information being local council offices (31.1\%), local newspapers (11.6\%) and public libraries (10.4\%). The majority $(71.6 \%)$ believed that their local council was not doing enough to inform them about cutbacks. In making their own feelings known on this issue, significant proportions would contact local councillors (20.3\%), their local MP (19\%) and local council offices (17.5\%), although over a quarter $(26.2 \%)$ were again not interested in making their feelings known. 
The next part of the survey focused on what might be termed survival information, i.e. information that might help individuals to overcome the problems that occur in day-to-day life. It asked whether or not respondents had encountered a problem relating to employment, education, housing or welfare benefits, and elicited brief details on the nature of these problems plus the information sources used to help solve the problems. In total, 328 (36.5\%) of the respondents indicated that they had had a problem relating to one or more of the four issues (see Table 2).

Table 2. Type of problem encountered

\begin{tabular}{|l|c|c|}
\hline Type of problem & No. & \% \\
\hline Employment problem & 141 & 15.7 \\
\hline Education problem & 118 & 13.1 \\
\hline Housing problem & 122 & 13.6 \\
\hline Welfare benefits problem & 135 & 15.0 \\
\hline $\begin{array}{l}\text { Total who cited one or more of } \\
\text { the above problems }\end{array}$ & 328 & 36.5 \\
\hline
\end{tabular}

141 respondents (15.7\%) indicated that they had had an employment problem, including finding work (the most common problem, cited by 71 respondents), dealing with redundancy or unfair dismissal, and sexual harassment or bullying in the workplace. Job centres and newspapers were the information sources used most frequently to help respondents solve employment problems. Interestingly, employment problems were cited by a greater proportion of males (20.2\%) than females (12.9\%).

A smaller proportion $(118,13.1 \%)$ cited an education problem, such as selecting a school or university, obtaining funding and grants, and special needs or health problems affecting education. Local education authorities, schools and universities, and family and friends were the most frequently cited information sources. Unsurprisingly, education problems were cited more frequently by students and those aged 16-44.

Housing problems were indicated by 122 (13.6\%) respondents; these included obtaining council housing, dealing with problem neighbours, and homelessness. Most of these respondents had approached council housing departments and local councillors for help. Housing problems were cited most frequently by those aged 20-44.

Exactly $15 \%$ (135) of the respondents had had a welfare benefits problem. All were concerned with claiming or establishing entitlement to a wide range of benefits. The main 
sources of their information were Department of Social Security (DSS) Offices, CABx, council social services departments, and family and friends. A greater proportion of rural respondents (22.7\%) cited a benefits problem than did the urban respondents (13.5\%); while disabled respondents had encountered more problems than able-bodied respondents $(+11.9$ points).

The survey then explored the concept that exclusion from information creates disadvantage. Respondents were asked to give an example of an occasion when not being able to obtain information had proven a disadvantage and over a quarter (26.1\%) provided such an example. These related to a wide range of issues, including financial matters, consumer issues, and health and relationship problems. Interestingly, examples were cited more frequently by those respondents that might not normally be associated with disadvantage, i.e. those from higher social classes and those with a higher level of educational qualification. This might relate more to a lack of awareness of disadvantage amongst those in the lower social classes and the less well-educated.

The next section of the survey sought to measure how well-informed the respondents were about citizenship information matters, and to examine their levels of participation in the democratic process.

They were firstly asked how well informed they felt they were about five different citizenship topics: national politics, local politics, legal rights, welfare benefits and equal rights (see Table 3). The majority (i.e. between $50 \%$ and $70 \%$ ) felt well or adequately informed about these subjects, although over a quarter of the sample in each case felt poorly informed about legal rights, welfare benefits and local politics. Male respondents felt better informed than females about national politics (+14.7 points); while with regard to welfare benefits, disabled respondents were better informed than able-bodied respondents $(+16.9)$.

Table 3. Respondents' awareness of various citizenship topics

\begin{tabular}{|l|c|c|c|c|c|}
\hline Topic & Expert & $\begin{array}{c}\text { Well } \\
\text { informed }\end{array}$ & $\begin{array}{c}\text { Adequately } \\
\text { Informed }\end{array}$ & $\begin{array}{c}\text { Poorly } \\
\text { Informed }\end{array}$ & $\begin{array}{c}\text { Not } \\
\text { interested }\end{array}$ \\
\hline National politics & 1.0 & 24.2 & 44.1 & 13.9 & 16.5 \\
\hline Local politics & 0.6 & 16.5 & 40.5 & 27.2 & 15.0 \\
\hline Legal rights & 1.1 & 17.7 & 40.9 & 31.3 & 8.6 \\
\hline Welfare benefits & 2.1 & 17.1 & 31.8 & 30.7 & 17.8 \\
\hline Equal rights & 2.6 & 22.0 & 41.8 & 20.7 & 12.5 \\
\hline
\end{tabular}


Respondents were provided with a list of six types of group or association and asked if they were a member of any. Overall there were low levels of participation in these groups, with the highest proportions being for membership of leisure (32.4\%) and charitable (25.2\%) groups. Only small minorities were members of professional and trade associations (16.6\%), trade unions (13.6\%), pressure groups (6.9\%) or political parties (6.7\%). Membership of all types of group was higher amongst the better-educated respondents.

Respondents were asked how regularly they vote at elections. The numbers who said they always vote at national (77.2\%), local (65.8\%), and European (45.3\%) elections were higher than the most recent actual turnouts for these votes ${ }^{7,8,9}$, particularly for local elections, suggesting that respondents tend to overestimate their participation in this respect. In general, the proportions who always vote at all three types of election grew larger as the respondents grew older. The survey also asked respondents whether, apart from voting, they actively participated in the political process. Only a small proportion (10.2\%) participated in other forms of political activity, such as canvassing, campaigning, and attending political meetings. Participation was generally higher amongst the professional and managerial occupations, and those who had received a more advanced education.

The survey asked respondents for their opinion on the importance of freedom of information, and if they felt that access to accurate and unbiased information was important for exercising their rights as citizens. The vast majority ( $91.7 \%$ in both cases) felt that these issues were important, reinforcing the finding in the first survey which indicated that $94.3 \%$ of respondents believed that information access is important for exercising their rights. Respondents were also asked to explain why they had responded in the manner they did. In summary, freedom of information was felt to be: a basic democratic right; necessary to ensure politicians' accountability; and necessary in the current atmosphere of sleaze and corruption. Access to personal data was deemed a particularly significant issue. Respondents felt that access to accurate and unbiased information was essential to their capacity to make effective decisions or form opinions.

The next section of the survey paid particular attention to the use of Information and Communication Technologies (ICTs). In a closed question, respondents were asked about current levels of access to ICTs. Access to computers (39.3\%), the Internet (14.6\%) and satellite/cable television (26.4\%) in the home was limited, while only $12.6 \%$ (35.3\% of those in employment) had access to the Internet at work. Unsurprisingly, access to ICTs tended to decrease as respondents grew older. 
The respondents were asked if they would use computers to take part in any of four different democratic activities, if computers were available for them to use either at home, at work or in public places. Table 4 summarises the response. A slight majority in each case would be willing to use computers to vote, make their own feelings known or obtain government information, but there was a reluctance to use computers to participate in debates. In general, those respondents with a higher occupational classification and/or a higher academic qualification were more willing to use a computer for these purposes. Older people, people in rural areas and people with a disability were less willing to use computers than younger respondents, urban residents and able-bodied respondents. These findings reinforce concerns over specific groups deemed to be in danger of exclusion by increasing emphasis on ICTs in communications with government.

Table 4. Potential use of computers for democratic activities

\begin{tabular}{|l|c|c|c|}
\hline Activity & $\begin{array}{c}\text { Yes } \\
\mathbf{\%}\end{array}$ & $\begin{array}{c}\text { No } \\
\mathbf{\%}\end{array}$ & $\begin{array}{c}\text { Don’t know } \\
\mathbf{\%}\end{array}$ \\
\hline To vote in elections & 54.7 & 44.2 & 1.1 \\
\hline To take part in political debates & 35.0 & 63.5 & 1.5 \\
\hline $\begin{array}{l}\text { To let government know what you think about particular issues and } \\
\text { decisions }\end{array}$ & 53.5 & 46.1 & 0.4 \\
\hline To obtain official government information & 59.8 & 39.5 & 0.6 \\
\hline
\end{tabular}

Respondents were asked if they might have concerns over confidentiality if they were to use a computer to interact with government. Of those respondents who would use a computer to vote, $47.7 \%$ were worried about confidentiality. Similar figures were found amongst those who would use computers to debate $(47.5 \%)$ and provide feedback to government on particular issues $(50.6 \%)$.

From a list of five options, respondents were asked how they would prefer to make their own feelings known on a subject they felt strongly about. The majority of respondents $(66.4 \%)$ preferred the traditional method of writing to someone, with smaller proportions preferring to speak at a public meeting (5.8\%), debate by computer $(5.5 \%)$, phone in to a radio/TV debate $(4.7 \%)$, speak on a televised debate $(2.3 \%)$. A significant proportion of $15 \%$ were not interested in making their feelings known publicly.

The survey then turned its attention to the public's use of libraries and other information sources. From a list of 11 organisations, individuals and locations, respondents were asked 
from which one they would prefer to obtain official government information. The results are illustrated in Table 5. Public libraries were the most popular source, cited by over $43 \%$ of respondents. This is a significant reinforcement of the finding in the first survey, where $77.3 \%$ of respondents indicated that they would approach libraries for information on at least an occasional basis. Interestingly, disabled respondents, when compared with the ablebodied, had a preference for approaching $\mathrm{CABx}$ (+15.4 points) but were less inclined to visit a library (-13.7).

Table 5. Preferred source of Government information

\begin{tabular}{|l|r|r|}
\hline Source & No. & \% \\
\hline Public libraries & 388 & 43.2 \\
\hline Post offices & 132 & 14.7 \\
\hline Citizens Advice Bureaux & 108 & 12.0 \\
\hline Local MP & 52 & 5.8 \\
\hline Local council offices & 49 & 5.5 \\
\hline Offices of Govt. departments and agencies & 36 & 4.0 \\
\hline Schools & 32 & 3.6 \\
\hline A computer in a public place, such as a shopping centre & 31 & 3.5 \\
\hline Banks and building societies & 18 & 2.0 \\
\hline Medical centres and doctors' surgeries & 9 & 1.0 \\
\hline Community and leisure centres & 4 & 0.4 \\
\hline
\end{tabular}

The respondents were also asked for what reasons they would prefer to obtain information from their chosen source. For most respondents it was the accessibility and the fact that they visited it regularly that made the library their preference; libraries were also seen as reputable and having an appropriate atmosphere. Those that preferred MPs and government departments were motivated by getting their information directly from the primary source. $\mathrm{CABx}$ were felt to have very helpful staff (libraries did not rate highly here) and were also seen as particularly reputable. Overall, the primary motivating factors appeared to be accessibility and frequency of visit.

$72.5 \%$ of the respondents were members of a public library; this is higher than the recently quoted national figure of $58 \%^{10}$, and interesting given the survey methodology and demographics of the sample. Membership was higher amongst the higher social classes and the better-educated and was lowest amongst those seeking work (64.6\%) or running a home $(63.9 \%)$.

Respondents were asked if they felt that public libraries were suitable places for obtaining information on the following five topics: their local council, welfare benefits, job 
opportunities and careers, housing, and consumer advice. Their response is illustrated in Table 4. The vast majority (82\%) believed that libraries were appropriate locations for council information, while smaller majorities in each case felt that libraries should hold information on the other four topics. There appeared to be some doubts over whether libraries should hold housing information, with $38.2 \%$ of respondents believing libraries to be unsuitable locations for such material.

Table 4. Suitability of public libraries for obtaining information on particular topics

\begin{tabular}{|l|c|c|c|c|}
\hline Topic & $\begin{array}{c}\text { Suitable } \\
\mathbf{\%}\end{array}$ & $\begin{array}{c}\text { Not suitable } \\
\mathbf{\%}\end{array}$ & $\begin{array}{c}\text { Don't know } \\
\mathbf{\%}\end{array}$ & $\begin{array}{c}\text { Not interested } \\
\mathbf{\%}\end{array}$ \\
\hline Your local council & 82.0 & 11.7 & 4.8 & 1.6 \\
\hline Welfare benefits & 65.1 & 27.4 & 5.4 & 2.0 \\
\hline Job opportunities and careers & 61.4 & 30.7 & 6.1 & 1.8 \\
\hline Housing & 53.5 & 38.2 & 6.3 & 2.0 \\
\hline Consumer advice & 67.8 & 23.6 & 6.5 & 2.1 \\
\hline
\end{tabular}

Those respondents who believed libraries were not appropriate places for the five types of information were asked to suggest more suitable locations. Local council offices were regarded as appropriate locations for council information; CABx, DSS offices and council social services departments were felt to be more suitable for benefits information; it was felt that jobs and career information should be located in job centres; council housing departments were deemed more appropriate for housing information; while $\mathrm{CABx}$ and Consumer Protection or Trading Standards offices were believed to be suitable for consumer information.

The survey then investigated the respondents' awareness of the types of information that public libraries hold. They were asked if they were aware that most libraries hold official government publications and information on health care, educational opportunities, legal rights and the European Union. Table 5 illustrates the response. Overall, $74.8 \%$ of respondents were unaware of at least one of the information types held by libraries, providing evidence of a real need for libraries to promote their collections more effectively. As can be seen, a small number of respondents stated that, while they did not actually know that libraries held this information, they would have presumed that they did so. There was less awareness of libraries holding government publications amongst the lower occupational classes and, with the exception of health care information, there was a greater awareness of library holdings amongst the better-educated respondents. 
Table 5. Awareness that particular types of information are held by most public libraries

\begin{tabular}{|l|c|c|c|}
\hline Type of information & $\begin{array}{c}\text { Aware } \\
\mathbf{\%}\end{array}$ & $\begin{array}{c}\text { Unaware } \\
\mathbf{\%}\end{array}$ & $\begin{array}{c}\text { Presumed } \\
\mathbf{\%}\end{array}$ \\
\hline Official government publications & 53.5 & 45.8 & 0.4 \\
\hline Health care & 53.6 & 45.1 & 1.0 \\
\hline Educational opportunities & 69.0 & 30.2 & 0.4 \\
\hline Legal rights & 53.7 & 44.9 & 1.1 \\
\hline European Union & 36.9 & 61.1 & 1.7 \\
\hline
\end{tabular}

Finally, those respondents who were unaware of at least one of the information types held by libraries were asked how libraries could let them know more about the types of information they hold. Publicity campaigns, leaflets and posters, exhibitions and displays, improved signposting and mailshots were all recommended. Unsurprisingly, non-members tended to emphasise the need for external publicity and mailshots, while current library members believed that there should be more promotion of materials in the library. Some respondents felt that libraries should not waste their resources by undertaking costly promotional activities.

\section{Conclusions}

The survey response (898 interviewees) was representative in most respects, but held greater proportions of women, the elderly, and the economically inactive than figures for the UK population as a whole. It is believed that high representation amongst these groups, who may face social exclusion, reveals particularly interesting results.

Significant current issues identified by respondents were dominated by Northern Ireland, education, health and Europe. The media was the prime source of information on most current issues, but for those respondents who wished to obtain further information public libraries would play a prominent role.

While the majority of respondents felt well-informed about the BSE crisis, they would like to find out more about the Single European Currency and local government cutbacks. The majority of respondents believed government should be doing more to provide information on all three topics. 
In terms of survival information, small but significant proportions of the sample had encountered employment (15.\%), education (13.1\%), housing (13.6\%) or welfare benefits $(15 \%)$ problems, and had utilised a variety of information sources and providers in order to solve these problems. Over a quarter of respondents cited an example of an occasion when a lack of information had proven a disadvantage.

The majority of respondents felt well informed about areas relating to citizenship, although more than a quarter were poorly informed in legal rights, welfare benefits and local politics.

There were low levels of participation in groups and societies. While respondents tended to overestimate their voting patterns, only small numbers participated in other forms of political activity, such as canvassing or campaigning.

A highly significant majority $(91.7 \%)$ of respondents felt that freedom of information and access to accurate and unbiased information were important in exercising their rights as citizens.

Access to ICTs is currently limited, although the majority felt that they would be prepared to use computers to vote and interact with government should computer access be more widely available. Most respondents, however, preferred to make their feelings known on an issue by writing to someone.

The preferred source of government information was the public library (43.2\%), with only post offices and $\mathrm{CABx}$ figuring significantly otherwise. For most respondents it was the accessibility of the public library and the fact that they visited it regularly that made libraries their preference. $72.5 \%$ of respondents were public library members.

The majority of respondents felt that public libraries were suitable places for finding information on their local council, consumer issues, welfare benefits, jobs and careers and housing, although there was little evidence that many had approached libraries for such information in the past. Very significant numbers were unaware that public libraries held European Union information, government publications, and information on health care, legal rights and educational opportunities, thus providing evidence of a real need for libraries to promote more effectively their collections and expertise in such areas. 


\section{References}

${ }^{1}$ Marcella, R., and Baxter, G. A national survey of the citizenship information needs of the general public. Aslib Proceedings 51(4), 1999, pp.115-121.

${ }^{2}$ Office of Population Censuses and Surveys. 1991 Census Small Area Statistics. Available through the University of Manchester's Manchester Information Datasets and Associated Services (MIDAS) http://cs6400.mcc.ac.uk/ (visited March 1998)

${ }^{3}$ Office of Population Censuses and Surveys. Standard Occupational Classification. (London: HMSO, 1990 (vols 1 \& 2), 1991 (vol 3).)

${ }^{4}$ Office for National Statistics. Annual abstract of statistics, 1997 edition. (London: The Stationery Office, 1997.)

${ }^{5}$ Office for National Statistics. Social trends, 1997 edition. (London: The Stationery Office, 1997.)

${ }^{6}$ Office for National Statistics. Regional trends, 1997 edition. (London: The Stationery Office, 1997.)

${ }^{7}$ Austin, T., ed. The Times guide to the House of Commons, May 1997. (London: Times Books, 1998.)

${ }^{8}$ Rallings, C., Temple, M., and Thrasher, M. Participation in local elections. In: Pratchett, L., and Wilson, D., eds. Local democracy and local government. (Basingstoke: Macmillan Press, 1996.)

${ }^{9}$ Morgan, R., ed. The Times guide to the European Parliament, June 1994. (London: Times Books, 1994.)

${ }^{10}$ Library and Information Commission. New library: the people's network. (London: LIC, 1997.) 